\title{
Health care costs in the last four years of life for private health plan beneficiaries in Brazil
}

\author{
Marcos Bosi Ferraz, ${ }^{1}$ Isaura Cristina Miranda, ${ }^{2}$ Jorge Padovan, ${ }^{2}$ \\ Patricia Coelho de Soárez, ${ }^{2}$ and Rozana Ciconelli ${ }^{1}$
}

Suggested citation Ferraz MB, Miranda IC, Padovan J, Soárez PC, Ciconelli R. Health care costs in the last four years of life for private health plan beneficiaries in Brazil. Rev Panam Salud Publica. 2008;24(2):120-6.

ABSTRACT Objective. To examine health care use and expenditures by Brazilians covered by private health care plans in the last four years of life.

Methods. Health plan provider enrollee files and death certificate data were used for 274 health plan beneficiaries who died in 1998, 1999, and 2000. Resources used for a beneficiary in the year of death and in the three years prior to death were identified. Descriptive statistical analyses were used for clinical and socio-demographic characteristics and to describe the costs. Results. Of the 274 deaths included in this analysis, 92 occurred in 1998, 82 in 1999, and 100 in 2000. Most of the deceased were males (61.4\%). Distribution in terms of type of health plan coverage (full versus hospitalization-only coverage) was similar among beneficiaries (53\% had hospitalization only and $47 \%$ had full coverage). The total health plan expenditure in the last four years of life for the 274 decedents was US\$26300 283 (US\$ 12287723 for beneficiaries with hospitalization-only and US\$ 14012560 for those with full coverage). Expenditures increased progressively in the four years preceding death. About $70 \%$ of medical expenses for decedents in the four years of this analysis were incurred in the last year of life. Conclusion. Relatively large amounts of health care resources are used by Brazilian private health plan participants in their last year of life, suggesting that specific strategies are needed to optimize the allocation of medical care resources for these patients.

Key words Death; health care costs; insurance, health; terminal care; Brazil.

In most populations, life expectancy has increased progressively, generating the need for extended health care

\footnotetext{
Rheumatology Division, Federal University of São Paulo and São Paulo Center for Health Economics, Brazil. Send correspondence to: Marcos Bosi Ferraz, Rua Botucatu 685, Vila Clementino, São PauloSP, Postal code: 04022-063, Brazil; telephone: 55 (11) 5549 0158; fax: 55 (11) 5549 0158; e-mail: marcos.ferraz@fleury.com.br.

2 São Paulo Center for Health Economics, Brazil.
}

for those who now live longer. The significant rise in the incidence of $\mathrm{CO}^{-}$ morbidities and progress in the diagnosis and treatment technologies that are available to extend and improve life have had an impact on the ageing population. Extended life expectancy has been pointed to as the main determinant of increased health care costs in industrialized nations $(1,2)$. Some authors suggest that rather than the age of a patient, the last months of life and the technological interventions now available are the most important factors determining increased health costs $(3,4)$.

The consequent increase in health care costs is challenging and has motivated intensive research for better strategies for the health care system. The specialized literature suggests that terminal patients receive most of their 
health care in the last days, weeks, or months prior to death, which could have an important impact on the health care system (5-8).

Hoover et al. (9) compared medical expenses in the last year of life for elderly patients (over 65 years old) and people of the same age group who did not die (survivors) within the study time frame. The authors observed that between 1992 and 1996, the average medical expense for decedents 65 years old and older in their last year of life was US\$ 37581 compared with US\$ 7365 for the control (survivor) group. Age at the time of death did not impact significantly on the mean total cost.

Scitovsky (10) looked at the health care received in the last 12 months of life and the potential relationship with age, functional status, and medical care. The author observed that patients 65 to 79 years old with good functional status received significantly more hospital and medical intensive care than did older individuals (80 years or older) who received more supportive measures. Total expenses in the older group (80 years or older) were slightly lower than in the 65-79-year age group. The report concluded that more investigation is needed, including studies with larger samples, before we can say that higher health costs in the last years of life are due to the inappropriate use of high technology in health care.

This is doubtless an issue of great interest, since it can have a direct impact on the planning and development of health care strategies. The health system has been continuously challenged to improve its efficacy by improving the quality of medical services and reducing costs $(1,11)$. An understanding of the factors related to the use of resources and to the increased costs in the last years of life can lead to more rational use of scarce resources (12-15).

The allocation of health care resources also raises important philosophical and ethical questions. All individuals, at least theoretically, should have the right to receive health care, and one's health care budget should be equally distributed throughout life. If one's health care budget is gradually used up over time, any additional unexpected costs at the end of life could be detrimental to the health care of other individuals involved in the same system (3).

An important element to bear in mind when evaluating health costs is the importance of palliative care to patient treatment. In the community of caregivers, there is general consensus that some heroic measures are obligatory in certain circumstances, governed by professional standards (16). However, if an intervention to prolong life cannot provide a minimal quality of residual life, it must be reconsidered. These palliative measures contribute to a substantial increase in health care costs toward the end of life. This discussion, however, goes beyond cost alone, and the decision to withdraw life-sustaining treatment is difficult for all concerned, involving ethical considerations, uncertainty about the prognosis, and potential caregiver remorse.

The issue of whether or not it is "worth" investing in patients in the last year or two of their lives is one of values and ethics and, while certainly important, is outside the scope of this paper.

Our purpose here is to analyze the use and costs of hospital and ambulatory health care by beneficiaries of a private health plan in São Paulo, Brazil, in the last four years of their life. All beneficiary deaths between 1998 and 2000 and the costs related to their health care were systematically analyzed.

\section{MATERIALS AND METHODS}

The study sample consisted of all beneficiaries (274 individuals) enrolled in a private health care plan in São Paulo, Brazil, who died in 1998, 1999, and 2000. The sample was selected from the health care payer database, which identified beneficiaries by name and identity number. Using this information, resources used for a beneficiary in the year of his or her death and in the three years prior were identified. The data covered health care resources used between 1995 and 2000.
The analyses are based on the cost incurred on the date of payment; the date the services were provided was not included in this analysis. Expenses were converted from the Brazilian real ( $\mathrm{R} \$$ ) to U.S. dollars using the average exchange rate for the period (US\$ $1.00=$ $\mathrm{R} \$ 1.30)$. Our analysis does not intend to assess opportunity costs, but rather to examine the totality of health care expenses in the last four years of life. This analysis also excludes all of the costs associated with loss of productivity and any expense that may have been paid directly by the beneficiary, his family, or a financial source other than the health care provider. This analysis is based on the health care payer perspective and includes only those expenses effectively recognized and paid for by the payer.

Costs in the year of death were those incurred in the 365 days before death. A similar definition was used to determine costs in the three years prior to death.

To facilitate an understanding of the data presented, some definitions of cost categories that reflect the health plan policies are described in Table 2 and Figure 1 . The confidentiality of the data has been maintained as patients are identified by initials, and the data were not evaluated individually.

Clinical and socio-demographic data, along with the costs associated with health care, have been submitted to descriptive statistical analysis. Ttests were used to compare the two coverage groups (full coverage and hospital-only coverage) in terms of age at death, health care resources used, and the costs incurred in the four years prior to death. The results were considered significant at the 0.05 level.

\section{RESULTS}

The data were obtained directly from the health care payer. The costs refer to total financial expenditures recorded in the payer database that are directly related to beneficiaries who died in 1998, 1999, and 2000. A total of 274 beneficiaries died in this period. 
Ninety-two deaths occurred in 1998, 82 in 1999, and 100 in 2000.

Table 1 shows the number of deaths according to gender and age group. Deaths were more frequent among men $(61.3 \%)$, and most deaths $(77 \%)$ occurred after 60 years of age.

The distribution of study subjects by type of health service used (consultations, diagnostic services, clinical and surgical hospitalization, home care, maternity care, urgent care, and emergency room services) during the years of the study is shown in Table 2. Slightly more beneficiaries had hospitalization-only coverage $(53 \%)$, but the difference is not statistically significant $(P<0.001)$. All of the deceased used consultations, diagnostic services, and clinical and surgical hospitalization, with about $20 \%$ using these services at least once in the four years prior to death. Clinical and surgical hospitalizations corresponded to $37.8 \%$ of the services used by the deceased in the period of the study.

The relative and cumulative distribution of costs for the patients who died in 1998, 1999, and 2000 according to the health services used is presented in Figure 1. Most of the costs (84.64\%)

TABLE 1. Gender and age distribution of 274 decedents enrolled in a private health plan in Brazil; 1998-2000

\begin{tabular}{|c|c|c|c|c|c|c|}
\hline \multirow[b]{2}{*}{ Age group } & \multicolumn{2}{|c|}{ Male } & \multicolumn{2}{|c|}{ Female } & \multicolumn{2}{|c|}{ Total } \\
\hline & No. & $\%$ & No. & $\%$ & No. & $\%$ \\
\hline $0-10$ & 3 & 1.8 & 2 & 1.9 & 5 & 1.8 \\
\hline $11-20$ & 4 & 2.4 & 0 & 0 & 4 & 1.5 \\
\hline $21-30$ & 4 & 2.4 & 1 & 0.9 & 5 & 1.8 \\
\hline $31-40$ & 4 & 2.4 & 4 & 3.8 & 8 & 2.9 \\
\hline $41-50$ & 7 & 4.2 & 2 & 1.9 & 9 & 3.3 \\
\hline $51-60$ & 19 & 11.4 & 14 & 13.2 & 33 & 12.0 \\
\hline $61-70$ & 29 & 17.3 & 19 & 18.0 & 48 & 17.5 \\
\hline $71-80$ & 78 & 46.5 & 34 & 32.0 & 112 & 40.9 \\
\hline$\geq 81$ & 20 & 12.0 & 30 & 28.3 & 50 & 18.2 \\
\hline Total & 168 & 61.3 & 106 & 38.7 & 274 & 100.0 \\
\hline
\end{tabular}

are related to clinical $(42.71 \%)$ and surgical $(41.93 \%)$ hospitalizations. Consultations and diagnostic services accounted for $1.47 \%$ and $3.27 \%$ of costs, respectively.

The distribution of total and relative costs in the year of death and in the prior three years by age group is shown in Figure 2. In absolute terms, the most expensive age groups in decreasing order were 71-80-year-olds, 6170 -year-olds, and those $\geq 81$ years old.
However, extremes of age (0-10 years old and $\geq 81$ years old) were associated with higher relative costs when compared with the other age groups.

Differences in health costs according to the type of coverage of the deceased (full coverage or hospitalization-only) were not statistically significant $(P<$ $0.001)$. The data show that the costs for both types of coverage are higher in months 1 to 12 before death (accounting for $70.8 \%$ of costs for beneficiaries

TABLE 2. Type of private health plan coverage and use of health services by year of death for 274 beneficiaries in Brazil; 1998-2000

\begin{tabular}{|c|c|c|c|c|c|c|c|c|}
\hline \multirow[b]{2}{*}{ Type of plan and services used } & \multicolumn{2}{|c|}{$\begin{array}{c}\text { Deaths in } \\
1998\end{array}$} & \multicolumn{2}{|c|}{$\begin{array}{c}\text { Deaths in } \\
1999\end{array}$} & \multicolumn{2}{|c|}{$\begin{array}{c}\text { Deaths in } \\
2000\end{array}$} & \multicolumn{2}{|c|}{ Total } \\
\hline & No. & $\%$ & No. & $\%$ & No. & $\%$ & No. & $\%$ \\
\hline Hospitalization-onlya & 47 & 51.0 & 45 & 34.9 & 54 & 54.0 & 146 & 53.3 \\
\hline Full coverage ${ }^{b}$ & 45 & 49.0 & 37 & 45.1 & 46 & 46.0 & 128 & 46.7 \\
\hline Clinical hospitalization ${ }^{c}$ & 136 & 20.2 & 120 & 19.3 & 152 & 20.2 & 408 & 20.0 \\
\hline Exams $^{d}$ & 134 & 19.9 & 116 & 18.7 & 155 & 20.6 & 405 & 19.7 \\
\hline Consultations $^{e}$ & 139 & 20.6 & 108 & 17.4 & 128 & 17.0 & 375 & 18.3 \\
\hline Surgical hospitalization $^{f}$ & 114 & 17.0 & 124 & 19.9 & 127 & 16.9 & 365 & 17.8 \\
\hline Urgent careg & 88 & 13.0 & 73 & 11.7 & 89 & 11.8 & 250 & 12.2 \\
\hline Emergency $^{\mathrm{h}}$ & 56 & 8.3 & 62 & 10.0 & 78 & 10.4 & 196 & 9.6 \\
\hline Home care ${ }^{i}$ & 7 & 1.0 & 19 & 3.0 & 21 & 2.8 & 47 & 2.3 \\
\hline Maternityj & 0 & 0.0 & 0 & 0.0 & 2 & 0.3 & 2 & 0.1 \\
\hline
\end{tabular}

a Hospitalization-only: benefits for medical services in a hospitalization setting only.

${ }^{b}$ Full coverage: benefits for outpatient services provided by a primary care physician or specialist, as well as hospitalization and diagnostic services.

c Clinical hospitalization: hospitalization due to any clinical cause.

d Exams: diagnostic medical tests prescribed during consultation.

${ }^{e}$ Consultations: visits of a patient to a physician or other health professional, performed in the physician's or other health professional's office.

f Surgical hospitalization: hospitalization for surgical procedures.

$g$ Urgent care: urgent medical care without the need for clinical observation or hospitalization.

${ }^{\mathrm{h}}$ Emergency care: medical services provided in the emergency room with potential clinical observation or hospitalization.

i Home care: medical assistance at home which is related to, and followed previous hospitalization. The main conditions considered for home care are: patients 65 years or older with three or more hospitalizations due to the same cause/procedure in one year; patients with chronic diseases such as heart failure, chronic obstructive pulmonary disease, cerebrovascular disease, and diabetes mellitus; patients recovering from trauma with fractures and osteoarticular disease; patients with cancer.

i Maternity: all costs related to pregnancy and delivery. 
FIGURE 1. Cumulative costs for health services during four-year period prior to death for private health plan beneficiaries in Brazil; 1995-2000

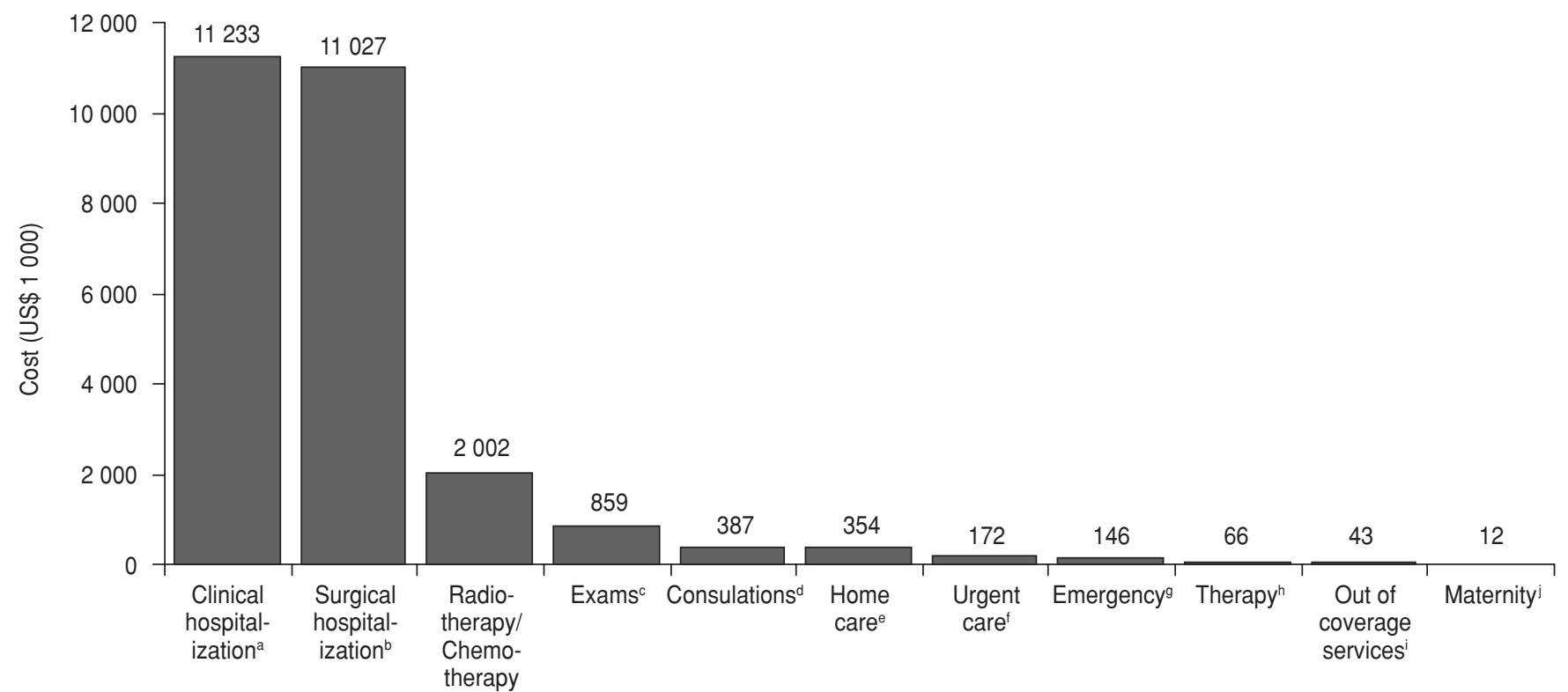

Note: Expenses were converted from the Brazilian real $(\mathrm{R} \$)$ using the average exchange rate for the period (US\$1.00= R $\$ 1.30)$.

a Clinical hospitalization: hospitalization due to any clinical cause.

b Surgical hospitalization: hospitalization for surgical procedures.

c Exams: diagnostic medical tests prescribed during consultation.

${ }^{d}$ Consultations: visits of a patient to a physician or other health professional, performed in the physician's or other health professional's office.

e Home care: medical assistance at home which is related to, and followed previous hospitalization. The main conditions considered for home care are: patients 65 years or older with three or more hospitalizations due to the same cause/procedure in one year; patients with chronic diseases such as heart failure, chronic obstructive pulmonary disease, cerebrovascular disease, and diabetes mellitus; patients recovering from trauma with fractures and osteoarticular disease; patients with cancer.

f Urgent care: urgent medical care without the need for clinical observation or hospitalization.

9 Emergency care: medical services provided in the emergency room with potential clinical observation or hospitalization.

h Therapy: costs related to medication or any other therapy.

i Out of coverage services: services and procedures not covered under the health plan contract, such as chiropractic services, acupuncture, etc.

i Maternity: all costs related to pregnancy and delivery.

FIGURE 2. Distribution of health care costs incurred by private health plan beneficiaries in the four years prior to death, by age group; Brazil

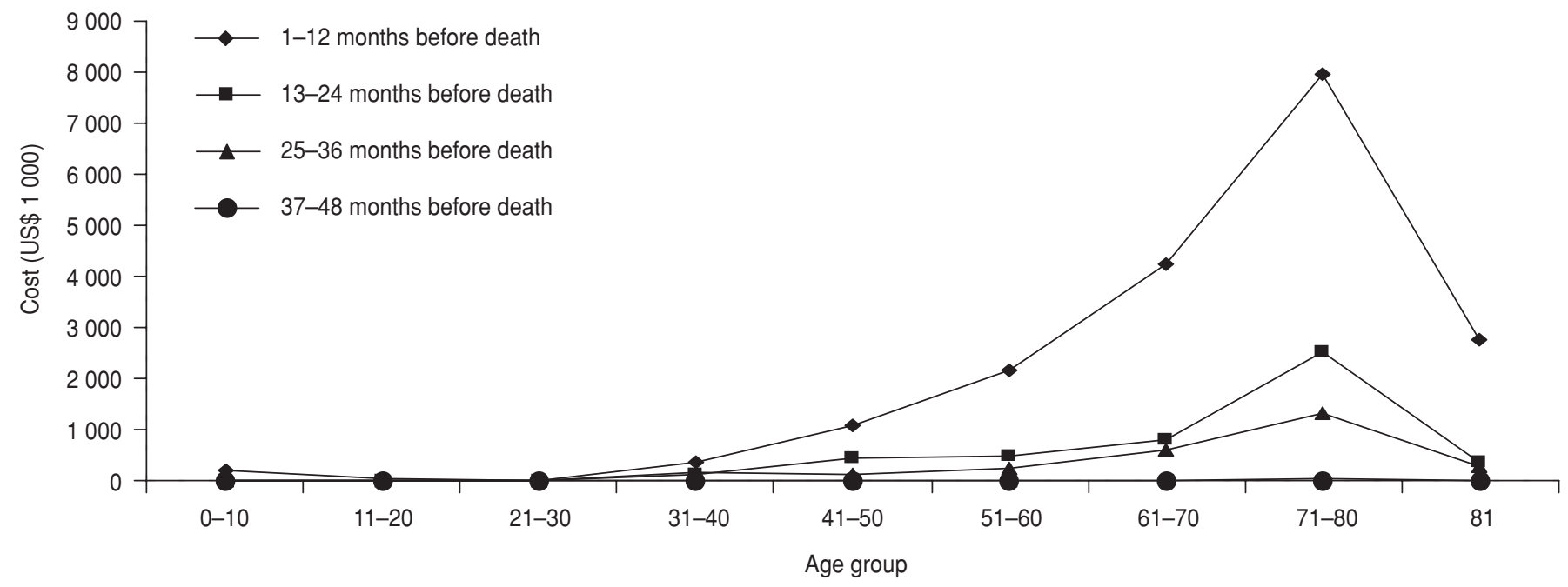


TABLE 3. Total costs and cumulative percentage of costs for private health plan beneficiaries in their last 12 months of life according to the type of health plan coverage (full coverage versus hospitalization-only), Brazil

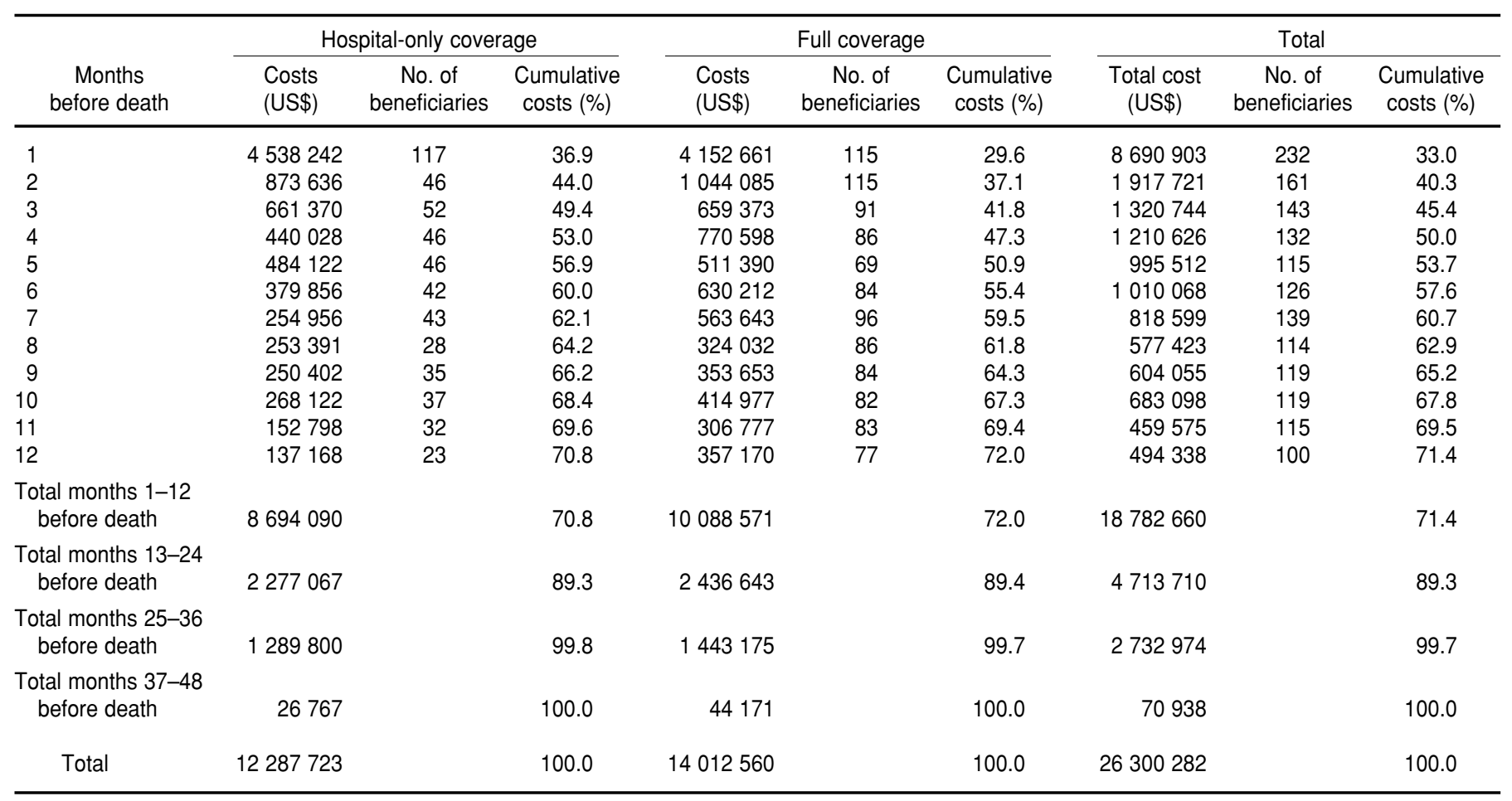

Note: Expenses were converted from the Brazilian real using the average exchange rate for the period (US $\$ 1.00=R \$ 1.30$ ).

Cents were rounded off to the nearest whole dollar.

with hospitalization-only and $72.0 \%$ for those with full coverage) and in months 13 to 24 before death $(18.5 \%$ for beneficiaries with hospitalization-only coverage and $17.4 \%$ for those with full coverage). Table 3 displays the costs of health care services in the last 12 months of life. In the four months prior to death, the costs correspond to about $50 \%$ of the total costs in the 48 months analyzed. This distribution does not differ significantly between the two types of coverage. The data also show that as death approaches, costs progressively increase in the 48 months analyzed.

\section{DISCUSSION}

This study shows that most of the costs related to beneficiary health care, about $70 \%$ of the total, occur in the last year of life. Costs decrease progressively from the year of death to the fourth year prior to death. Age group analysis shows a similar pattern.
Most of the deaths occurred in the 71-80-year-old group, and health costs were higher in these patients as compared to the other age groups. Van Vliet and Lamers (17) evaluated costs in the seven years prior to death in the general population and observed that costs per person-year in the last calendar year of life were 15.3 times the average spent on survivors. For decedents younger than 65 years old, this number was 27.3 times the average, and for those over 65 years old, it was 4.7 times the average. These results differ from our study, where health care costs were highest for 71-80-year-olds. In our study we observed that the highest costs were related to hospitalization. No significant difference was observed in hospitalizations due to clinical or surgical problems $(P<0.001)$. Following hospitalization costs, the most expensive were radiotherapy or chemotherapy costs. Other authors have found similar results (18). In the United States, $27 \%$ to $30 \%$ of Medicare costs each year are as- sociated with only $5 \%$ to $6 \%$ of the beneficiaries that die in that particular year. Much of the cost in the last month of life is related directly to hospitalization (19).

Costs associated with death are similar in both types of health care plans analyzed in our study. An explanation would be that patients with hospitalization-only plans are hospitalized more often than those with full coverage, and receive a number of procedures covered by the plan during their stay in hospital.

Liu and Yang (20) examined health care use and expenditures in the last year of life for adults covered by Taiwan's National Health Insurance (NHI). They selected 9369 adult decedent beneficiaries from NHI enrollee files and death certificate data files for 1999. Ten thousand randomly sampled adult NHI beneficiaries who were alive on 31 December 1999 were selected as a survival control group. The total NHI expenditure in the last year of life for the 9369 decedents was 
US\$ 71.6 million. About $54.5 \%$ of all medical expenses in the last year of life were incurred in the last three months of life. In our study we observed that about $50 \%$ of the total costs occurred in the last four months before death.

In Brazil, the public health care system or Sistema Único de Saúde (SUS) provides universal coverage and is financed mostly by general taxation. All 183 million Brazilian citizens have the right to SUS coverage, but the system has coverage and quality problems and is mainly used by low-income groups. Some 37 million people, those regularly employed and in the middleand upper-income levels have private insurance. Because our study sample was served by a private health care plan, it is not representative of the poorest segments of the population, but it does include different socioeconomic categories. Twenty-five percent of the decedents were from middleand upper-income brackets and able to pay their own private insurance. Seventy-five percent of decedents were from lower socioeconomic categories with health insurance provided sky NG, Saynina O, et al. Managed care, hospice use, site of death, and medical care expenditures in the last year of life. Arch Intern Med. 2002;162(15):1722-8

2. Levinsky NG, W Yu, Ash A, Moskowitz M, Gazelle G, Saynina O, et al. Influence of age on Medicare expenditures and medical care in the last year of life. JAMA. 2001;286(11): 1349-55.

3. Felder S. Cost of dying: alternatives to rationing. Health Policy. 1997;39(2):167-76.

4. Madsen J, Serup-Hansen N, Kristiansen IS. Future health care costs-do health care costs during the last year of life matter? Health Policy. 2002;62(2):161-72.

5. Lubitz JD, Riley GF. Trends in Medicare payments in the last year of life. N Engl J Med. 1993;328(15):1092-6.

6. Lubitz J, Cai L, Kramarow E, Lentzner H. Health, life expectancy and health care spending among the elderly. N Engl J Med. 2003; 349(11):1048-55.

7. Stearns SC, Norton EC. Time to include time to death? The future of health care expenditures predictions. Health Econ. 2004;13(4): 315-27.

8. Stooker T, van Acht JW, van Barneveld EM, van Vliet RC, van Hout BA, Hessing DJ, et al. Costs in the last year of life in the Netherlands. Inquiry. 2001;38(1):73-80. by their employers. Had the study subjects belonged to the poorest segments of the population we can assume that the costs would have been lower, as these persons would have had less access to health care services.

This work has some limitations. First, it is a retrospective study; its quality and reliability depend on the accuracy and availability of the original data. Because the data came from the payer database (cost accounting system), it is likely to be reliable (21). Second, we analyzed the amounts charged by and paid to the health care provider, which may or may not reflect actual resource consumption or costs. Third, because this analysis adopted the perspective of the payer, important indirect costs were not considered. Costs related to productivity losses for the beneficiaries, their families, and caregivers were not taken into account in our study, nor were expenses directly paid by the beneficiaries or other sources. The conclusions are therefore limited by the cost categories used.

Our results demonstrate that the highest costs related to death occur in

\section{REFERENCES}

9. Hoover DR, Crystal S, Kumar R, Sambamoorthi U, Cantor JC. Medical expenditures during the last year of life: findings from the 1992-1996 Medicare current beneficiary survey. Health Serv Res. 2002;37(6):1625-42.

10. Scitovsky AA. Medical care in the last twelve months of life: the relation between age, functional status and medical care expenditures. Milbank Q. 1988;66(4):640-60.

11. Hogan C, Lunney J, Gabel J, Lynn J. Medicare beneficiaries' costs of care in the last year of life. Health Aff (Millwood). 2001;20(4):188-95.

12. Kessler DP, McClellan MB. Advance directives and medical treatment at the end of life. J Health Econ. 2004;23(1):111-27.

13. O'Neill C, Groom L, Avery AJ, Boot D, Thornhill K. Age and proximity to death as predictors of GP care costs: results from a study of nursing home patients. Health Econ. 2000; 9(8):733-8.

14. Shugarman LR, Campbell DE, Bird CE, Gabel J, Louis TA, Lynn J. Differences in Medicare expenditures during the last 3 years of life. J Gen Intern Med. 2004;19:127-35.

15. Wilson DM, Truman CD. Addressing myths about end-of-life care: research into the use of acute care hospitals over the last five years of life. J Palliat Care. 2002;18(1):29-38.

16. Reynolds S, Cooper AB, McKneally M. Withdrawing life-sustaining treatment: ethical the last year of life, more specifically in the four months prior to death. Higher costs were observed for people in the 71-80-year age group as compared with the other age groups. No significant difference in costs was observed between the two types of health plans analyzed-hospitalization-only or full coverage $(P<0.001)$.

Substantial health care resources are used by Brazilian private health plan participants in their last year of life, suggesting that specific strategies are needed to optimize the allocation of medical care resources to these patients.

This study addresses an issue that has been analyzed extensively in industrialized nations, but little research has been done in Brazil and other developing nations. As the Brazilian population ages, end-of-life health care costs will become critical to the financing and management of the nation's health care services. Further economic studies are needed to provide an empirical measurement of health care resource utilization and costs in the last years of life. considerations. Thorac Surg Clin. 2005;15(4): 469-80.

17. van Vliet RC, Lamers LM. The high costs of death: should health plans get higher payments when members die? Med Care. 1998; 36(10):1451-60.

18. Brockmann H. Why is less money spent on health care for the elderly than for the rest of the population? Health care rationing in German hospitals. Soc Sci Med. 2002;55(4): 593-608.

19. Miller SC, Intrator O, Gozalo P, Roy J, Barber $\mathrm{J}$, Mor V. Government expenditures at the end of life for short- and long-stay nursing home residents: differences by hospice enrollment status. J Am Geriatr Soc. 2004;52(8):1284-92.

20. Liu CN, Yang MC. National health insurance expenditure for adult beneficiaries in Taiwan in their last year of life. J Formos Med Assoc. 2002;101(8):552-9.

21. Melfi CA. Using databases for studying and comparing health care costs and resource use. Pharmacoepidemiol Drug Saf. 2001;10(5): 399-402.

Manuscript received on 9 January 2007. Revised version accepted for publication on 26 February 2008. 
RESUMEN Objetivo. Examinar la utilización de los servicios de salud y los gastos asociados durante los últimos cuatro años de vida de brasileños con seguro privado de salud.

Costos de la atención sanitaria en los últimos cuatro años de vida de beneficiarios de seguros privados de salud en Brasil

Palabras clave Muerte, costos de la atención en salud, seguro de salud, cuidado terminal, Brasil.
Métodos. Se emplearon los expedientes del seguro y los certificados de defunción de 274 beneficiarios de seguros de salud que murieron entre 1998 y 2000. Se identificaron los recursos utilizados para cada beneficiario durante el año que murió y los tres años anteriores. Mediante métodos estadísticos descriptivos se analizaron las características clínicas y sociodemográficas y se describieron los costos.

Resultados. De los 274 fallecidos analizados, 92 murieron en 1998, 82 en 1999 y 100 en 2000; la mayoría de ellos $(61,4 \%)$ eran hombres. La distribución según el tipo de seguro de salud fue similar (cobertura total: $47 \%$; solo cobertura de hospitalización: $53 \%$ ). El gasto total del seguro de salud en los últimos cuatro años de vida de los 274 fallecidos fue de US\$26300283 (US\$ 12287723 para los beneficiarios con cobertura de hospitalización solamente y US\$ 14012560 para los que tenían cobertura total). Los gastos aumentaron progresivamente en los cuatro años previos a la muerte. Cerca de $70 \%$ de los gastos médicos de los fallecidos en los cuatro años analizados correspondieron al último año de vida.

Conclusiones. Los brasileños con seguro médico privado utilizan una cantidad relativamente grande de recursos sanitarios en su último año de vida, por lo que se requieren estrategias específicas para optimizar la asignación de recursos de atención médica para estos pacientes. 